\title{
IN VITRO PROBIOTIC POTENTIAL OF ENTEROCOCCUS SPECIES ISOLATED FROM TUNGRYMBAI, A FERMENTED SOYBEAN PRODUCT OF MEGHALAYA, INDIA
}

\author{
B. Malakar, A.J. Das and S.C. DekA* \\ Department of Food Engineering and Technology, Tezpur University, Assam-784028. India
}

(Received: 22 June 2015; accepted: 05 January 2016)

\begin{abstract}
Lactic acid bacteria were isolated from tungrymbai, a traditional fermented soybean product of Meghalaya, India and assessed for their probiotic properties. Survival under simulated gastric conditions was tested and five acid tolerant strains were selected. By using 16S rDNA sequencing, these isolates were confirmed to be Enterococcus species. The strains exhibited good survivability in high concentrations of bile salts. The strains were susceptible to antibiotics and they were also found to inhibit growth of Staphylococcus aureus and Escherichia coli. The strains were gelatinase negative and non-haemolytic. The strains also assimilated cholesterol up to a certain level. The study confirmed that all identified five strains have in vitro probiotic properties.
\end{abstract}

Keywords: fermented soybean, Enterococcus, probiotic

Soybean (Glycine max) is an important source of proteins. It is also popular for its high nutritional value viz. vitamin A, B, C, and minerals. The production of tungrymbai (fermented product prepared from soybean) is a traditional art carried out by the Khasi tribe of Meghalaya, India. The colour of the product is brown with a characteristic odour and mild pungency (DAS \& DeKa, 2012). The Khasis enjoy this food because of the acquired taste and also due to the health benefits associated with its consumption (Agrahar-MurugKar \& Subbulakshmi, 2006). The high crude protein content of fermented soy products may be attributed to the microbiota developed during fermentation of these products (GUPTA et al., 2007). The biological activity of fermented soybean foods is mainly due to isoflavones that exhibit estrogenic, antioxidative, antiosteoporotic, and anti-carcinogenic activities (SAMrUAN et al., 2012). Lactic acid bacteria (LAB) are the most common and dominant microorganisms present in fermented foods. They are generally recognized as safe organisms (GRAS) to be used as probiotics (FULLER, 1989). Reports indicate that LAB and their fermented products are effective at enhancing innate and adaptive immunity, prevent gastric mucosal lesion development, alleviate allergies, and put up defence against intestinal pathogen infection. LAB have been reported to be useful as health adjuncts and are commonly added to food as the delivery mechanism (CHOU \& WEIMER, 1999). Many health benefits are reported owing to the consumption of fermented foods and some of these health benefits correlate to the beneficial effects brought about by the intake of microorganisms. Thus, investigation of probiotic organisms with new and potentially powerful tools will facilitate the development of the bacteria as therapeutic agents, and provide the mechanisms to produce advanced probiotic strains (CALLANAN, 2005). On the basis of the above scenarios, this study was aimed at isolating LAB from tungrymbai, to identify them and to test their probiotic properties. It is

\footnotetext{
* To whom correspondence should be addressed.

Phone: +919435408396; fax: +913712-267005; e-mail: sankar@tezu.ernet.in
} 
expected that this study will further help in incorporation of these strains for the production of functional foods.

\section{Materials and methods}

\subsection{Sampling and isolation of lactic acid bacteria}

Samples of tungrymbai were collected from four different places of the state of Meghalaya, India. Lactobacillus plantarum ATCC 8014, Staphylococcus aureus MTCC 3160, and Escherichia coli MTCC 40 were provided by the Department of Food Engineering and Technology, Tezpur University. L. plantarum ATCC 8014 is considered to be a safe and beneficial probiotic that allows its usage as a reference organism in this study (Pop et al., 2015). The chemicals (AR grade) and media used were obtained from Sigma-Aldrich Corporation, USA. LAB were isolated on MRS agar plates supplemented with bromocresol purple indicator for $48 \mathrm{~h}$ at $37^{\circ} \mathrm{C}$ under anaerobic conditions. The cells were Gram-stained and observed in a trinocular microscope (DM 3000, Leica Microsystems, Germany). For catalase test, few drops of $3 \% \mathrm{H}_{2} \mathrm{O}_{2}$ were pipetted over the growth on MRS slants. After purity controlling, cultures were maintained in MRS broth.

\subsection{Identification of isolates}

The isolates were grown in MRS broth for $24 \mathrm{~h}$ at $37^{\circ} \mathrm{C}$ and then pelleted by centrifugation. For the isolation and purification of genomic DNA, a DNA purification kit (K0512, ThermoScientific, EU) was used. Amplification was carried out in a thermocycler (Mastercycler Nexus Gradient, Eppendorf, USA) using PCR master mix, DNA template, and the 16S rRNA universal primers set consisted of "27f" forward primer (5'-GAGAGTTTGATCCTGGCTCAG-3') and "1495r" reverse primer (5'-CTACGGCTACCTTGTTACGA-3'). The conditions used were initial denaturation at $95^{\circ} \mathrm{C}$ for $3 \mathrm{~min}$, followed by 30 cycles of $94{ }^{\circ} \mathrm{C}(1 \mathrm{~min}), 55^{\circ} \mathrm{C}(1 \mathrm{~min}), 72{ }^{\circ} \mathrm{C}(1 \mathrm{~min})$, linked to $72{ }^{\circ} \mathrm{C}(10 \mathrm{~min})$, and then to $5{ }^{\circ} \mathrm{C}$. Purification of PCR product was done using a kit (K0701, Fermantas, EU). Electrophoresis of the purified PCR products were performed on $0.6 \%$ agarose gel and the ethidium bromide stained PCR-amplified bands were observed under UV illumination in the gel-doc system (MiniBIS Pro, DNR Bio-Imaging Systems, Israel). Amplified DNA was sequenced using an automated DNA sequencer (Instrument 3500, Applied Biosystems) by chain termination method. The DNA sequences obtained were converted to their FASTA form and organisms were identified by comparing each consensus sequences to a database library of known 16S rDNA using NCBI BLAST tool.

\subsection{Simulation of gastric conditions and bile tolerance test}

The growth of the isolates in simulated gastric conditions was performed by their growth in MRS broth with $\mathrm{pH}$ adjusted to 7, 3, and 2 with $5 \mathrm{~N} \mathrm{HCl}$ (HASSANZADAZAR et al., 2012). The tolerance of strains towards bile salts was evaluated in MRS broth supplemented with different concentrations ( 0.3 to $15 \%$ ) of bile salts (DorA \& GLENN, 2002). In both cases, 100 $\mu \mathrm{l}$ of actively growing $24 \mathrm{~h}$ culture of the strains were inoculated into $5 \mathrm{ml}$ of the appropriate test media in test tubes and incubated for $24 \mathrm{~h}$ under anaerobic conditions at $37^{\circ} \mathrm{C}$. After the end of incubation period, the viable cells were enumerated by pour plate counts on MRS agar plates after 10 -fold serial dilutions prepared in $0.1 \%$ peptone water. 
1.4. In vitro cholesterol lowering property and gelatine hydrolysis and haemolysis activity tests

The strains were grown in MRS broth containing $0.4 \%$ bile salt and $0.01 \%$ polyoxyethylenecholesteryl sebacate. The amount of cholesterol removed was calculated according to Eq. 1.

$\%$ Cholesterol removed $=1-\frac{\text { residual cholesterol in cell free broth }}{\text { cholesterol of control broth }} \times 100$

Cholesterol assimilated was expressed as the amount of cholesterol consumed in $\mathrm{mg} \mathrm{g}^{-1}$ of cells. Total cholesterol was analysed using the method of ATTARDE and co-workers (2010). Gelatinase activity was tested by the method of HARrigan and MCCANCE (1990) and haemolysis activity was investigated as described by GERHARDT and co-workers (1981). A strain of $S$. aureus was used as positive control.

\subsection{Antibiotic susceptibility test and detection of antimicrobial activity}

Sensitivity of the isolates to antibiotics was tested using different antibiotic discs on Antibiotic Susceptibility Test Media No. 2 (HiMedia, India) plated on $150 \mathrm{~mm}$ diameter Petri plates. The media were overlaid with the diluted cultures $\left(1-2 \times 10^{8} \mathrm{CFU} \mathrm{ml}^{-1}\right)$ of the test organism and the antibiotic discs were placed upon the inoculated agar surface. Incubation was done at $37^{\circ} \mathrm{C}$ under anaerobic conditions for $24 \mathrm{~h}$. The zones of inhibition were measured using an antibiotic zone scale to the nearest millimetre. The diameters of the zones are related to the susceptibility of the isolate and to the diffusion rate of the antibiotic through the agar medium (BAuER et al., 1966). Antimicrobial activity of the isolates was studied by agar spot test (Schillinger \& LuCKe, 1989). The indicator strains were E. coli MTCC 40 and S. aureus MTCC 3160. The antimicrobial activity was evaluated by zone of inhibition and expressed in $\mathrm{mm}$.

\section{Results and discussion}

\subsection{Screening for growth under simulated gastric conditions (acid tolerance)}

Acid tolerance is one of the first properties screened while selecting probiotic strains, since the most important and desirable property of probiotic bacteria is their ability to remain viable under acidic conditions of the gastrointestinal tract (TuOmola et al., 2001). All isolates

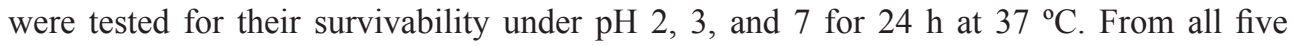
samples, the most tolerant strains were selected and their results are shown in Table 1. All the isolates except BASTU2 had counts above $6 \log \mathrm{CFU}$ at $\mathrm{pH} 7$ and all of them survived at $\mathrm{pH}$ 3. BASTU3, BASTU4, and BASTU5 showed higher level of tolerance by surviving at $\mathrm{pH} 2$ and showed counts of 5.57, 4.00, and $4.30 \log \mathrm{CFU} \mathrm{ml^{-1 }}$, respectively. On the other hand, $L$. plantarum ATCC 8014 showed count of $6.87 \log \mathrm{CFU} \mathrm{ml}{ }^{-1}$ at $\mathrm{pH} 3$ and $7.67 \log \mathrm{CFU} \mathrm{m} l^{-1}$ at $\mathrm{pH} 7$. 
Table 1. Effect of $\mathrm{pH}$ on survivability

\begin{tabular}{lccc}
\hline Strain name & \multicolumn{3}{c}{ Count in log $\mathrm{CFU} \mathrm{m}^{-1}$} \\
\cline { 2 - 4 } & $\mathrm{pH} 7$ & $\mathrm{pH} 3$ & $\mathrm{pH} 2$ \\
\hline Enterococcus faecium BASTU1 & 6.96 & 4.00 & 0 \\
Enterococcus faecium BASTU2 & 4.53 & 4.48 & 0 \\
Enterococcus faecium BASTU3 & 7.57 & 6.00 & 5.57 \\
Enterococcus lactis BASTU4 & 7.51 & 5.85 & 4.00 \\
Enterococcus faecium BASTU5 & 7.47 & 5.86 & 4.30 \\
Lactobacillus plantarum ATCC8014 & 7.62 & 5.49 & 4.11 \\
\hline
\end{tabular}

\subsection{Identification of bacterial strains}

The total counts of LAB isolated from soya product ranged from 8.98 to $9.02 \log _{\mathrm{CFU} \mathrm{g}}{ }^{-1}$ in all collected samples. All five isolates were found to be Gram-positive and catalase negative, which are indicative traits of the LAB group. The isolates BASTU1, BASTU2, BASTU3, BASTU4, and BASTU5 were identified to belong to the species E. faecium, E. faecium, E. faecium, E. lactis, and E. faecium, respectively, and the NCBI accession numbers obtained for these identified strains were KJ690925, KJ690923, KJ690924, KJ857034, and KJ857035, respectively. Enterococci belong to the LAB and are of specific importance in foods due to their involvement in the utilization as probiotics. E. faecium and E. faecalis strains are used as probiotics and are consumed in high numbers in the form of pharmaceutical preparations. In humans, these enterococcal probiotics are administered to treat diarrhoea, antibioticassociated diarrhoea, irritable bowel syndrome, to lower cholesterol levels, or to improve host immunity. Till date, there have been no reports of disease caused by enterococcal probiotics that are currently on the market. Moreover, some of these strains, such as $E$. faecium SF68 and E. faecalis Symbioflor, were investigated for their safety and are available in the market for more than 20 years without any reported problems (FrANZ et al., 2011).

Along with other bacteria that are part of the normal flora, E. faecalis prevents the colonization of pathogenic bacteria in the body of its host by competing with the pathogens for binding sites and nutrients. It also enhances the immune system by inducing the production of low levels of antibodies against its own components, which, in turn, makes the immune system more efficient. These characteristics of E. faecalis can also be used for the production of probiotic products, which are dietary supplements and foods that help to treat conditions such as infectious diarrhoea, IBS, and tooth decay. E. faecalis produces bacteriocin (a substance of proteinaceous character with inhibitory activity) that prevents the growth of several other bacteria, such as Listeria monocytogenes, Staphylococcus aureus, and Vibrio cholerae, thereby preventing the spoilage of dairy products (LivESTRONG, 2013).

\subsection{Growth at different bile salts concentrations, cholesterol assimilation, gelatinase and haemolytic activity}

Bile stability is a very important criterion of an effective probiotic bacterium. The probiotic microorganisms taken orally have to defend against the bile salt in the gastrointestinal tract, the strong acid medium in the stomach, since it must transit through the stomach and small intestine in order to colonize the human gastrointestinal tract (GunN, 2000; Tuomola et al., 2001). The results of bile salts concentration's effect on the survivability of the isolated 
Enterococcus species are shown in Table 2. It was found that E. faecium BASTU3, E. lactis BASTU4, and E. faecium BASTU5 showed highest survivability till $15 \%$ of bile salt concentration with plate count of $7.39 \log \mathrm{CFU} \mathrm{m} \mathrm{m}^{-1}, 7.40 \log \mathrm{CFU} \mathrm{m} \mathrm{m}^{-1}$ and $7.11 \log$ CFU ml $\mathrm{m}^{-1}$, respectively. E. faecium BASTU-2 survived till 4\% showing plate count of $7.32 \log$ CFU ml ${ }^{-1}$, E. faecium BASTU1 survived till 3.5\% with plate count of $6.93 \mathrm{log}$ CFU ml ${ }^{-1}$. L. plantarum ATCC 8014 on the other hand showed count of $6.69 \log$ CFU ml ${ }^{-1}$ at $15 \%$ bile salt concentration. REHAIEM and co-workers (2014) also reported the probiotic properties of $E$. faecium MMRA and observed no decrease in the viable count (in $0.3 \%$ bile salt) up to $300 \mathrm{~min}$ of incubation.

Table 2. Bile tolerance test

\begin{tabular}{|c|c|c|c|c|c|c|c|c|c|c|c|c|c|c|}
\hline \multirow[t]{2}{*}{ Strain } & \multicolumn{14}{|c|}{ 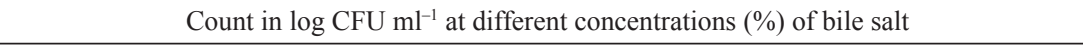 } \\
\hline & $\begin{array}{l}\text { Con- } \\
\text { trol }\end{array}$ & 0.3 & 0.5 & 1.0 & 1.5 & 2.0 & 2.5 & 3.0 & 3.5 & 4.0 & 6.0 & 8.0 & 10.0 & 15.0 \\
\hline $\begin{array}{l}\text { E. faecium } \\
\text { BASTU1 }\end{array}$ & 2.02 & 2.01 & 2.01 & 1.99 & 1.99 & 1.99 & 1.98 & 1.96 & 1.93 & 0 & 0 & 0 & 0 & 0 \\
\hline $\begin{array}{l}\text { E. faecium } \\
\text { BASTU2 }\end{array}$ & 2.09 & 2.08 & 2.06 & 2.04 & 2.03 & 2.01 & 1.99 & 1.96 & 1.91 & 1.90 & 0 & 0 & 0 & 0 \\
\hline $\begin{array}{l}\text { E. faecium } \\
\text { BASTU3 }\end{array}$ & 1.64 & 1.63 & 1.61 & 1.60 & 1.60 & 1.59 & 1.58 & 1.57 & 1.55 & 1.54 & 1.53 & 1.50 & 1.49 & 1.49 \\
\hline $\begin{array}{l}\text { E. lactis } \\
\text { BASTU4 }\end{array}$ & 1.64 & 1.63 & 1.63 & 1.62 & 1.61 & 1.61 & 1.60 & 1.60 & 1.59 & 1.58 & 1.57 & 1.56 & 1.55 & 1.54 \\
\hline $\begin{array}{l}\text { E. faecium } \\
\text { BASTU5 }\end{array}$ & 1.57 & 1.54 & 1.52 & 1.50 & 1.48 & 1.44 & 0.65 & 0.57 & 0.47 & 0.47 & 0.46 & 0.45 & 0.44 & 0.43 \\
\hline $\begin{array}{l}\text { L. plantarum } \\
\text { ATCC } 8014\end{array}$ & 2.29 & 2.21 & 2.15 & 2.08 & 2.02 & 1.97 & 1.93 & 1.86 & 1.84 & 1.77 & 1.75 & 1.71 & 1.68 & 1.33 \\
\hline
\end{tabular}

High level of serum cholesterol is associated with the risk of cardiovascular diseases and probiotic bacteria have demonstrated potential to lower cholesterol levels by different mechanisms, including cholesterol assimilation. Therefore, use of probiotic bacteria for reducing cholesterol has grabbed much attention (RAGHAVAN et al., 2011; TOMARO-DUCHESNEAU et al., 2014). E. lactis BASTU4 and E. faecium BASTU5 reduced the highest \% of cholesterol (Table 3). Cholesterol assimilation ranged from 16.21 to $29.19 \mathrm{mg}$ of cholesterol per $\mathrm{g}$ of cells and the highest value was recorded for E. faecium BASTU5 (Table 3). DorA and GLENN (2002) studied E. faecalis strains isolated from the human gut and found that the strains assimilated more than 1.5 times the average of the other strains in the media with 0.2 and $0.4 \%$ (w/v) ox gall. All the Enterococcus isolates, including L. plantarum ATCC 8014, showed negative gelatinase and haemolysis ( $\gamma$-haemolytic) activity. Absence of gelatinase activity and haemolytic activity are selection criteria for probiotic strains, indicating that these bacteria are non-virulent (DE VUYST et al., 2003). 
Table 3. Cholesterol assimilation test

\begin{tabular}{lcc}
\hline Strain & Reduction in cholesterol content $(\%)$ & Cholesterol assimilated $\left(\mathrm{mg} \mathrm{g}^{-1}\right)$ \\
\hline E. faecium BASTU1 & 52.13 & 16.21 \\
E. faecium BASTU2 & 61.16 & 19.46 \\
E. faecium BASTU3 & 74.88 & 24.18 \\
E. lactis BASTU4 & 76.13 & 26.24 \\
E. faecium BASTU5 & 84.16 & 29.19 \\
L. plantarum ATCC 8014 & 88.52 & 33.15 \\
\hline
\end{tabular}

\subsection{Antibiotic susceptibility}

Antibiotic susceptibility of isolates is a crucial criterion from the safety point of view of potential probiotics. The results for antibiotic susceptibility test are presented in Table 4 and all strains were susceptible to the tested antibiotics. E. faecium BASTU1 showed less susceptibility ( $10 \mathrm{~mm}$ to $16 \mathrm{~mm}$ ) against the antibiotics sulphatriad, bacitracin, polymyxin B, gentamicin, neomycin, and streptomycin. However, its susceptibility remained in the range of $21 \mathrm{~mm}$ to $29 \mathrm{~mm}$ for the other antibiotics and similar pattern was also shown by E. faecium BASTU2. E. faecium BASTU3 was found to be less susceptible against the antibiotics bacitracin, polymyxin B, gentamicin, neomycin, streptomycin, and sulphatriad as compared to the other antibiotics. E. lactis BASTU4 and E. faecium BASTU5 showed total susceptibility in similar pattern, and L. plantarum ATCC 8014 showed high susceptibility in the range of 11-35 mm. Specific antibiotic resistance determinants carried on mobile genetic elements are often detected in the typical probiotic genera, thus representing a safety issue. However, when mutations or intrinsic resistance mechanisms are responsible for the resistance phenotype, the antibiotic resistance in these organisms does not constitute a safety concern in itself (GUEIMONDE et al., 2013)

Table 4. Antibiotic susceptibility test

\begin{tabular}{|c|c|c|c|c|c|c|}
\hline \multirow[t]{2}{*}{ Antibiotics } & \multicolumn{6}{|c|}{ Zone of inhibition (mm) } \\
\hline & $\begin{array}{l}\text { E. faecium } \\
\text { BASTU1 }\end{array}$ & $\begin{array}{l}\text { E. faecium } \\
\text { BASTU2 }\end{array}$ & $\begin{array}{l}\text { E. faecium } \\
\text { BASTU3 }\end{array}$ & $\begin{array}{l}\text { E. lactis } \\
\text { BASTU4 }\end{array}$ & $\begin{array}{l}\text { E. faecium } \\
\text { BASTU5 }\end{array}$ & $\begin{array}{l}\text { L. plantarum } \\
\text { ATCC } 8014\end{array}$ \\
\hline Bacitracin - 10 units & 13 & 15 & 16 & 19 & 26 & 28 \\
\hline $\begin{array}{l}\text { Chloramphenicol } \\
-30 \mu \mathrm{g}\end{array}$ & 27 & 30 & 27 & 27 & 24 & 31 \\
\hline Penicillin $\mathrm{G}-10$ units & 21 & 25 & 23 & 24 & 18 & 29 \\
\hline Polymyxin B -300 $\mu \mathrm{g}$ & 12 & 15 & 14 & 10 & 16 & 22 \\
\hline Gentamicin $-10 \mu \mathrm{g}$ & 16 & 18 & 17 & 17 & 17 & 25 \\
\hline Neomycin $-30 \mu \mathrm{g}$ & 11 & 13 & 11 & 11 & 13 & 20 \\
\hline Ampicillin $-10 \mu \mathrm{g}$ & 29 & 28 & 29 & 31 & 32 & 35 \\
\hline Streptomycin $-10 \mu \mathrm{g}$ & 14 & 17 & 15 & 18 & 18 & 21 \\
\hline Sulphatriad $-300 \mu \mathrm{g}$ & 10 & 10 & 10 & 10 & 10 & 11 \\
\hline Tetracycline $-25 \mu \mathrm{g}$ & 29 & 31 & 33 & 34 & 33 & 35 \\
\hline
\end{tabular}




\subsection{Antimicrobial activity of the isolates}

Good probiotics should present their antimicrobial actions particularly to the pathogens in the GI system. All the studied Enterococcus strains were highly effective towards both the tested pathogenic bacteria, i.e., S. aureus and E. coli (Table 5). S. aureus is a major opportunistic human pathogen both in hospital and the community. Considerable research efforts have also been put to understand its complex pathogenesis (RASIGADE \& VANDENESCH, 2014)

\begin{tabular}{lcc}
\multicolumn{3}{c}{ Table 5. Antimicrobial activity test } \\
\hline Strain & \multicolumn{1}{c}{ Zone of inhibition (mm)* } \\
\cline { 2 - 3 } & S. aureus & E. coli \\
\hline E. faecium BASTU1 & $18.33 \pm 1.53$ & $26.00 \pm 1.00$ \\
E. faecium BASTU2 & $19.33 \pm 1.53$ & $25.33 \pm 1.53$ \\
E. faecium BASTU3 & $19.00 \pm 2.00$ & $25.67 \pm 0.58$ \\
E. lactis BASTU4 & $19.00 \pm 1.00$ & $25.00 \pm 1.00$ \\
E. faecium BASTU5 & $20.00 \pm 1.00$ & $26.33 \pm 1.15$ \\
L. plantarum ATCC 8014 & $21.00 \pm 1.00$ & $28.00 \pm 1.00$ \\
\hline
\end{tabular}

$*(\mathrm{n}=3) \pm \mathrm{SD}$

Even though E. coli can be an innocuous resident of the gastrointestinal tract, pathogenic variants of $E$. coli are a major public health concern as they have low infectious doses and are transmitted through ubiquitous mediums like food and water. They can cause a broad range of human diseases, such as infections in the gastrointestinal tract, urinary tract, bloodstream, and central nervous system (CROXEN et al., 2013). Highest activity against $S$. aureus was shown by E. faecium BASTU5, also E. faecium BASTU2, E. faecium BASTU3, and E. lactis BASTU4 exhibited good activity. In case of $E$. coli, the zones of inhibition were relatively larger than for $S$. aureus. Both E. faecium BASTU1 and E. faecium BASTU5 showed higher activity against $E$. coli than the other strains.

\section{Conclusions}

Phenotypic and genotypic identification confirmed that all five isolates from tungrymbai of Meghalaya, India were Enterococcus spp. The results of the present investigation support the importance of this fermented food. Further investigation, particularly at the molecular level, will help to consider these strains as the potential candidates for inclusion as starter cultures in fermentation processes and also to reveal their probiotic properties. Moreover, additional studies at the molecular level must ascertain that these strains follow EFSA rules and also to eliminate any gene of virulence factors if present. The future studies will certainly be beneficial to consumers by quantitatively confirming health benefits and also to manufactures by providing more information on the stability of the strains .

The authors are thankful to the Khasi community of Meghalaya, India for sharing their knowledge on the methodology of tungrymbai preparation. 


\section{References}

Agrahar-Murugkar, D. \& Subbulakshmi, G. (2006): Preparation techniques and nutritive value of fermented foods from the Khasi tribes of Meghalaya. Ecol. Food Nutr., 45, 27-38.

Attarde, D., Pawar, J., Chaudhari, B. \& Pal, S. (2010): Estimation of sterols content in edible oil and ghee samples. Int. J. Pharm. Sci. Rev. Res., 5, 135-137.

Bauer, A.W., Kirby, W.M.M., Sherris, J.C. \& Turk, M. (1966): Antibiotic susceptibility testing by a standardized single disk method. Am. J. Clin. Pathol., 45, 493-496.

Callanan, M. (2005): Mining the probiotic genome: advanced strategies, enhanced benefits, perceived obstacles. Curr. Pharm. Design, 11, 25-36.

Chou, L.S. \& Weimer, B. (1999): Isolation and characterization of acid and bile tolerant isolates from strains of Lactobacillus acidophilus. J. Dairy Sci., 82, 23-31.

Croxen, M.A., Law, R.J., Scholz, R., Keeney, K.M., Wlodarska, M. \& Finlay, B.B. (2013): Recent advances in understanding enteric pathogenic Escherichia coli. Clin. Microbiol. Rev., 26, 822-880.

Das, A.J. \& DekA, S.C. (2012): Mini review - Fermented foods and beverages of the North-East India. Int. Food Res. J., 19, 377-392.

De Vuyst, L., Foulquie, M.R \& Revets, H. (2003): Screening for enterocins and detection of hemolysin and vancomycin resistance in Enterococci of different origins. Int. J. Food Microbiol., 84, 299-318.

Dora, I.A.P. \& Glenn, R.G. (2002): Cholesterol assimilation by lactic acid bacteria and bifidobacteria isolated from the human gut. Appl. Environ. Microb., 68, 4689-4693.

Franz, C.M., Huch, M., Abriouel, H., Holzapfel, W. \& Gálvez, A. (2011): Enterococci as probiotics and their implications in food safety. Int. J. Food Microbiol., 151, 125-140.

Fuller, R. (1989): Probiotic in man and animals. J. Appl. Bacteriol., 90, 3452-3453.

Gerhardt, P., Murray, R.G.E., Costilow, R.N., Nester, E.W., Wood, W.A., Krieg, N.R. \& Phillips, G.B. (1981): Manual of methods for general bacteriology. American Society for Microbiology, Washington. 525 pages.

Gueimonde, M., Sánchez, B., de los Reyes-Gavilán, C.G. \& Margolles, A. (2013): Antibiotic resistance in probiotic bacteria. Front. Microbiol., 4, 202.

GunN, J.S. (2000): Mechanisms of bacterial resistance and response to bile. Microbes Infect., 2, 907-913.

Gupta, V., Sharma, A. \& Nagar, R. (2007): Preparation, acceptability and nutritive value of rabadi - a fermented moth bean food. J. Food Sci. Tech., 44, 600-601.

Harrigan, W.F. \& McCance, M.E. (1990): Laboratory methods in food and dairy microbiology. Academic Press, London. 452 pages.

Hassanzadazar, H., Ehsani, A., Mardani, K. \& Hesari, J. (2012): Investigation of antibacterial, acid and bile tolerance properties of lactobacilli isolated from Koozeh cheese. Vet. Res. Forum., 3, 181-185.

LiveSTRONG (2013): http://www.livestrong.com/article/244675-beneficial-uses-of-enterococcus-faecalis. (Last accessed on December 17, 2013).

Pop, O.L., Vodnar, D.C., Suharoschi, R., Mudura, E. \& Socaciu, C. (2015): L. plantarum ATCC 8014 entrapment with prebiotics and lucerne green juice and their behavior in simulated gastrointestinal conditions. J. Food Process. Eng., doi: 10.1111/jfpe.12234

Raghavan, C.M., Nanda, A., Yuvaraj, R., Kumar, D.J.M., Murugan, A.S. \& Raja, R.B. (2011): Assimilation of cholesterol by Lactobacillus species as probiotics. World Appl. Sci. J., 14, 552-560.

Rasigade, J.P. \& Vandenesch, F. (2014): Staphylococcus aureus: A pathogen with still unresolved issues. Infect. Genet. Evol., 21, 510-514.

Rehaiem, A., Belgacem, Z.B., Edalatian, M.R., Martínez, B., Rodríguez, A., Manai, M. \& Guerra, N.P. (2014): Assessment of potential probiotic properties and multiple bacteriocin encoding-genes of the technological performing strain Enterococcus faecium MMRA. Food Control, 37, 343-350.

Samruan, W., Oonsivilai, A. \& Oonsivilai, R. (2012): Soybean and fermented soybean extract antioxidant activities. World Acad. Sci. Eng. Technol., (WASET), 72, 1315-1318.

Schillinger, U. \& Lucke, F.K. (1989): Antibacterial activity of Lactobacillus sakei isolated from meat. Appl. Environ. Microb., 55, 1901-1906.

Tomaro-Duchesneau, C., Jones, M.L., Shah, D., Jain, P., Saha, S. \& Satya Prakash, S. (2014): Cholesterol assimilation by lactobacillus probiotic bacteria: An in vitro investigation. BioMed. Res. Int., doi: $10.1155 / 2014 / 380316$.

Tuomola, E., Crittenden, R., Playne, M., Isolauri, E. \& Salminen, S. (2001): Quality assurance criteria for probiotic bacteria. Am. J. Clin. Nutr., 73, 393-398. 